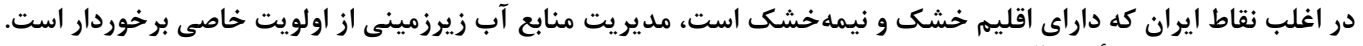

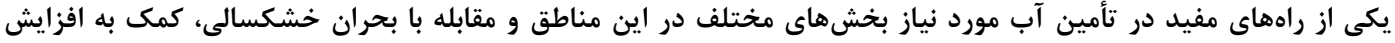

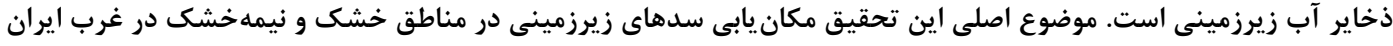

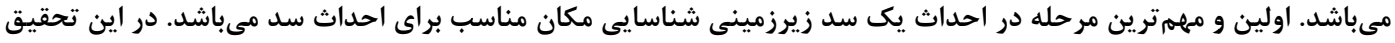

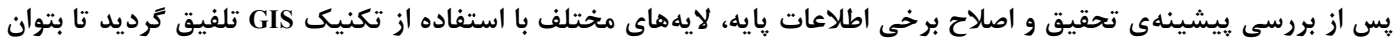

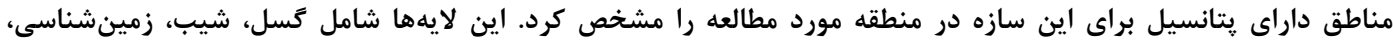

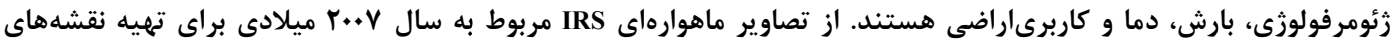

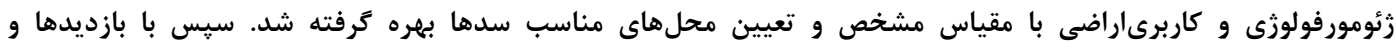

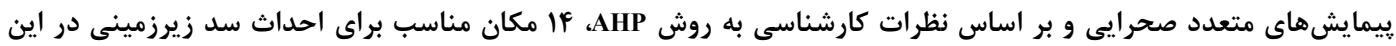
منطقه انتخاب ترديد.

وازههاى كليدى: سد زيرزمينى، GIS، استان ايلام، دشت مهران

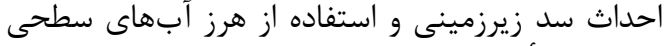

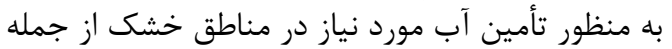

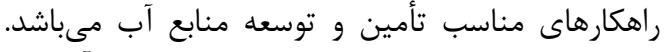

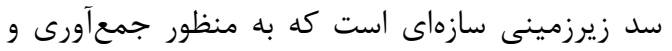

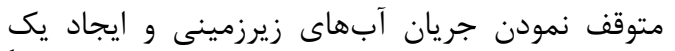

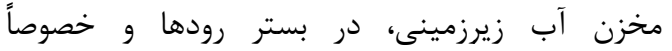

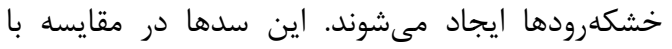

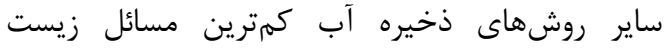

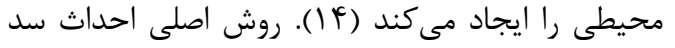

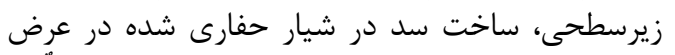

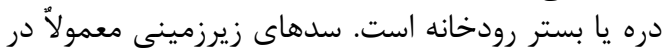

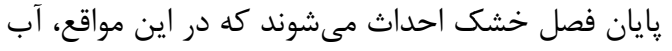
كمى در سفرهها موجود است و جريان كمى وجى وجود داث دارد

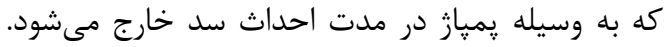

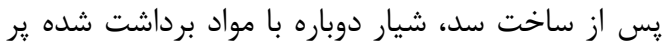

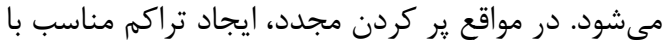

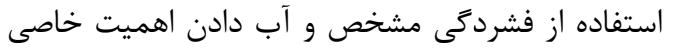

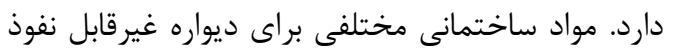

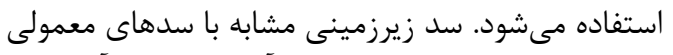

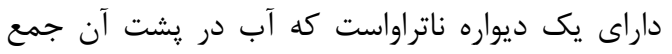
مىشود، جنس اين ديواره مى تواند رس متراكم، داري، سفال،

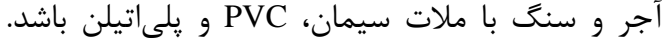

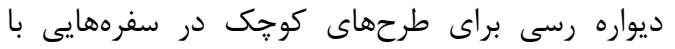

مقدمه

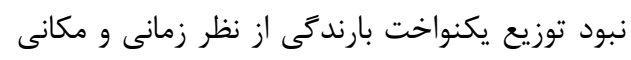

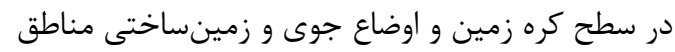

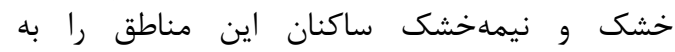

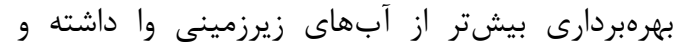

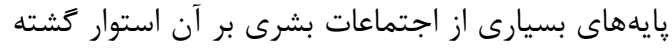

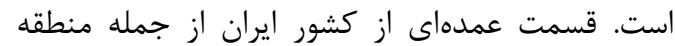

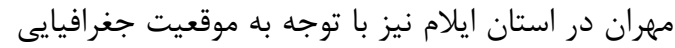
خاص خود جز مناطق خشك و نيمه خشك است،

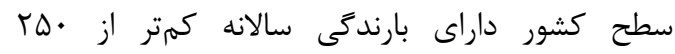

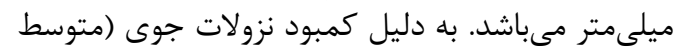

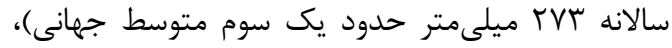

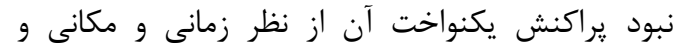

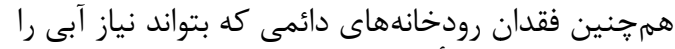

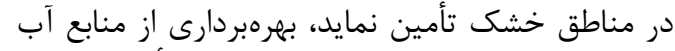

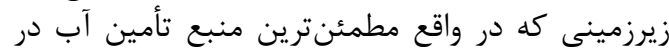

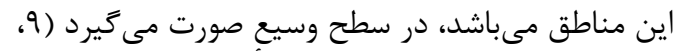

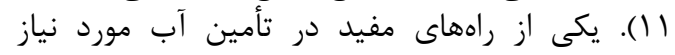

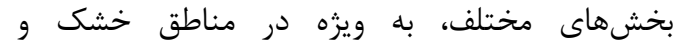

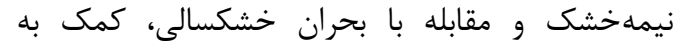

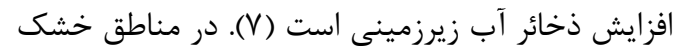

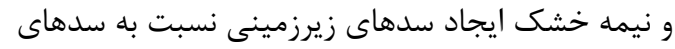

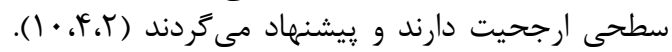




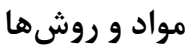

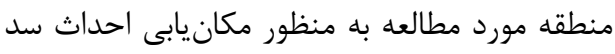

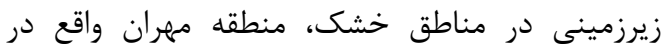

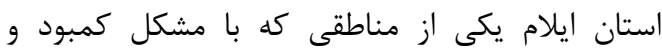

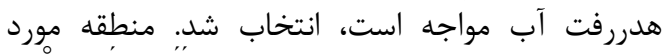

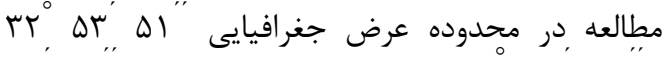

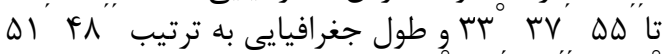
更 محدوة هof\&VI

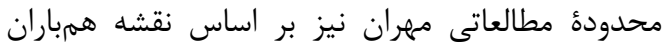

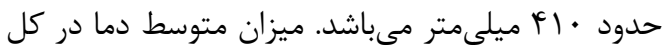

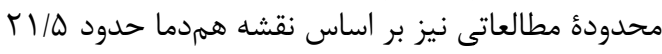

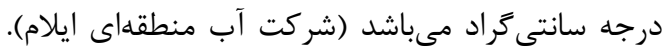

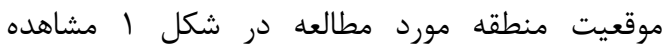

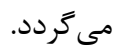

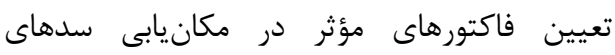

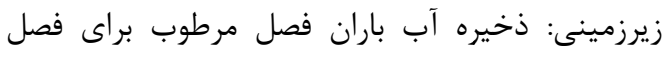

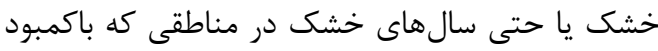

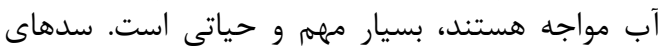

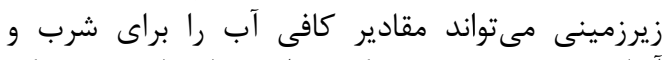

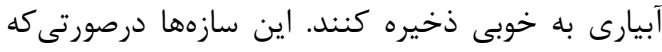

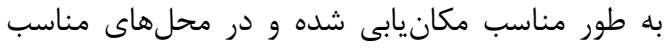

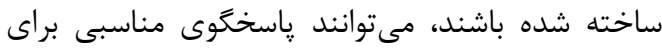

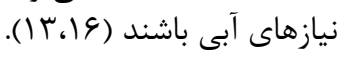

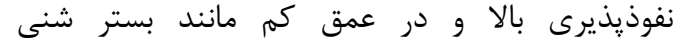

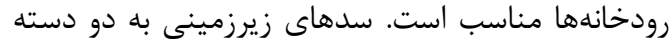

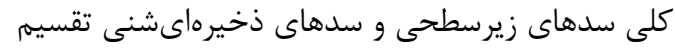

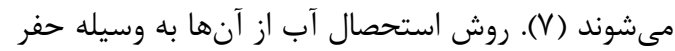

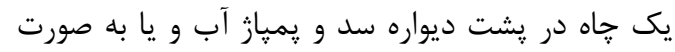

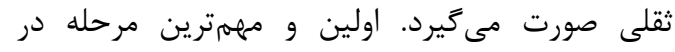

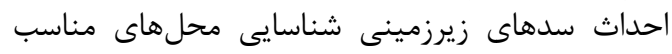

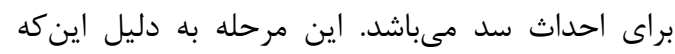

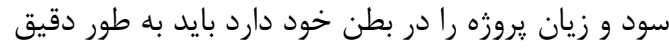
انجام شود. استفاده از تكنيكهاى

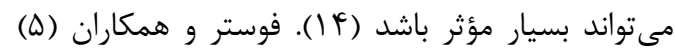

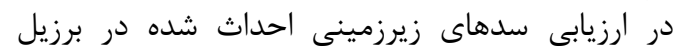

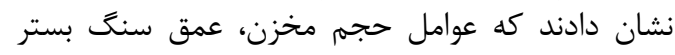

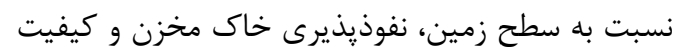

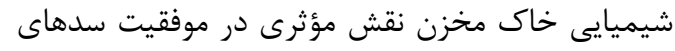

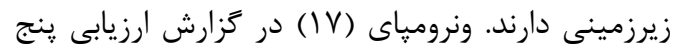

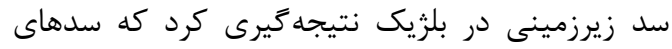

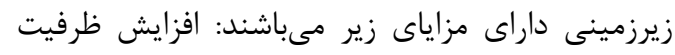

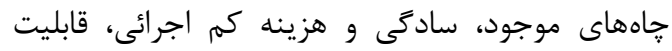

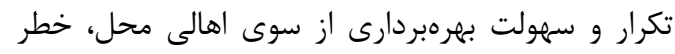

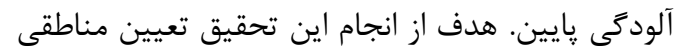

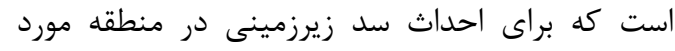

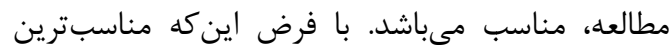

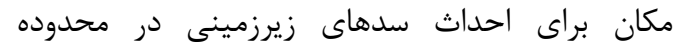

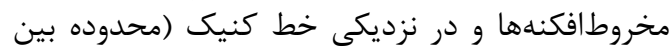
دشت و كوهستان) مى دياشد.

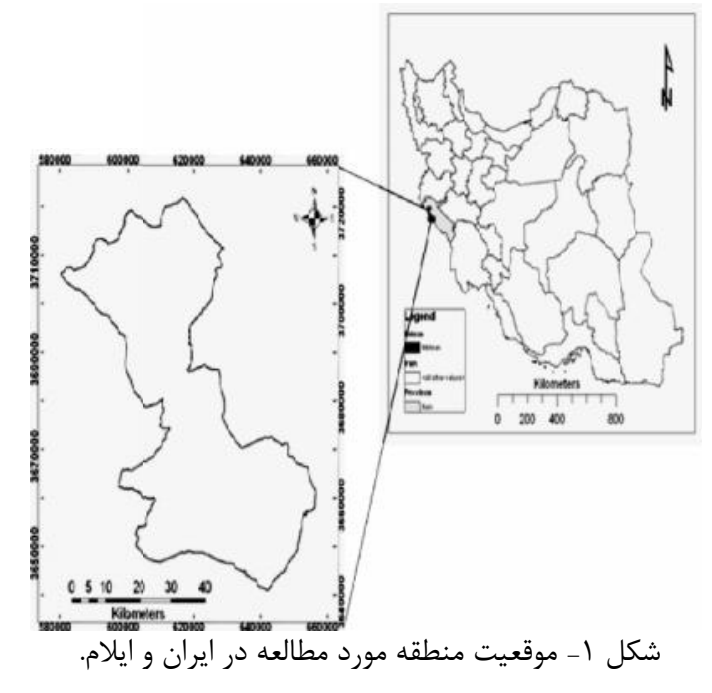

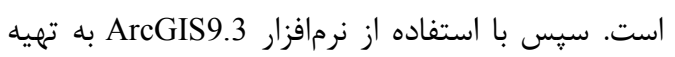

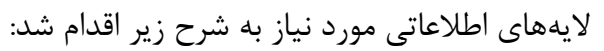

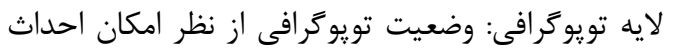

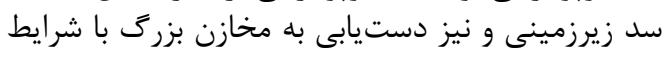

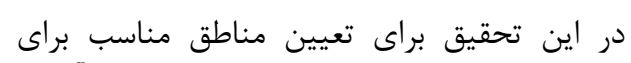

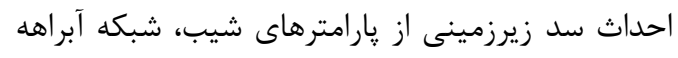

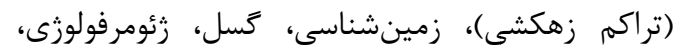
كاربرىاراضى، يوشش، اراضى و تويوكرافى استفاده شده 
رقومى ارتفاعى يا DEM با قدرت تفكيك • ب متر تهيه شد (شكل r) (r). لايه شيب: با توجه به برابل برسىهاى انجام شده حداكثر

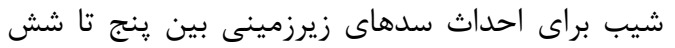

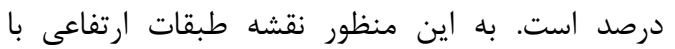

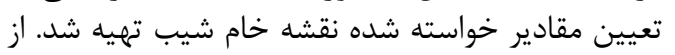

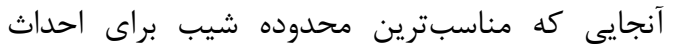

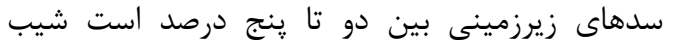

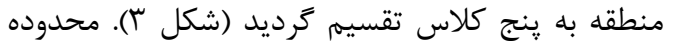
طبقهبندى شيب منطقه مهران در جدول آ آورده شده
تغذيه مناسب، تا حد زيادى تعيين كننده است بـ به

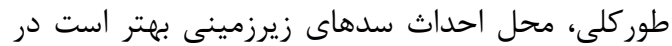

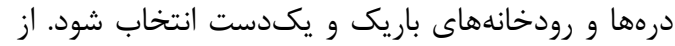

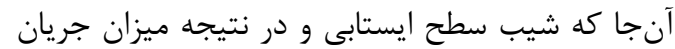

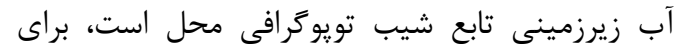

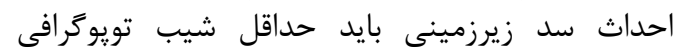

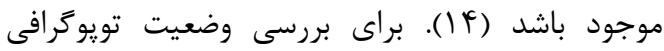

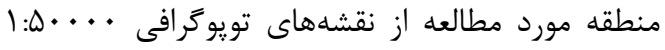

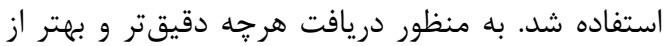
شرايط تويوگرافى منطقه و تغييرات ارتفاعى، لايه مدل مل دول

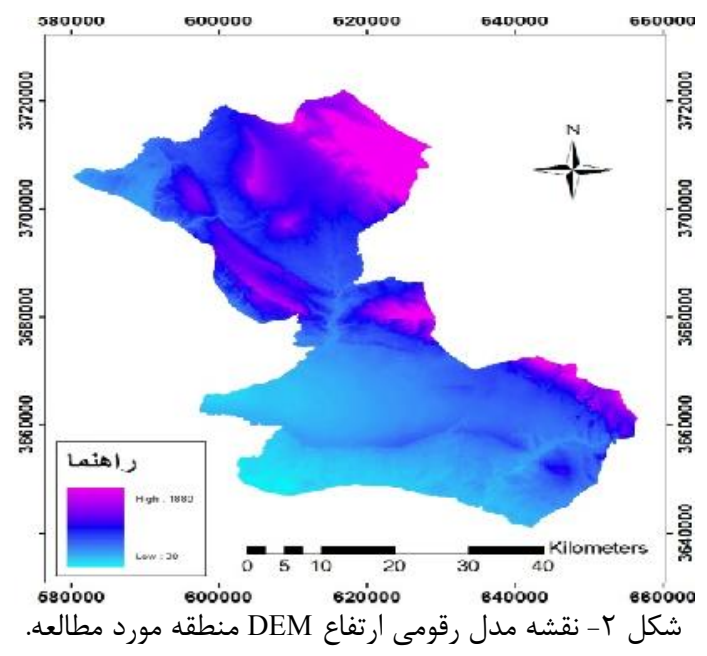

\begin{tabular}{|c|c|}
\hline طبقات شيب برحسب درصد & طبقات شيب براى محدوده هاى مناسب سدزيرزمينى \\
\hline$\cdot-r$ & بسيار مناسب \\
\hline$r-\omega$ & مناسب (1) \\
\hline$\Delta-V$ & مناسب (r) \\
\hline$v_{-1} \cdot$ & مناسب متوسط \\
\hline$>1$ & مناسب كم \\
\hline
\end{tabular}

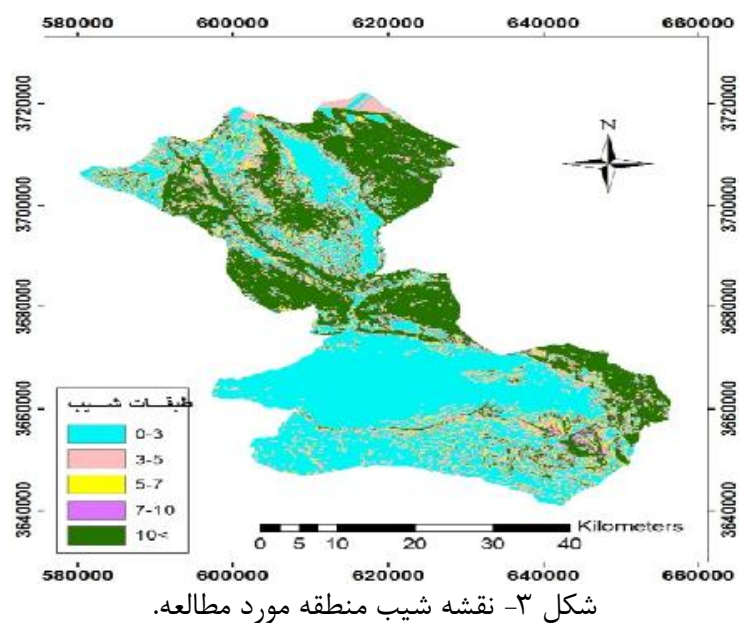


لايه كَل: يكى از عوامل اصلى نشت و فرار آب آز از

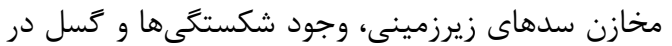

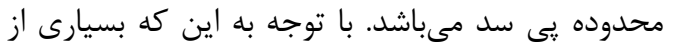

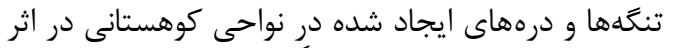

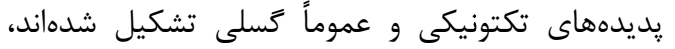

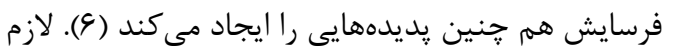

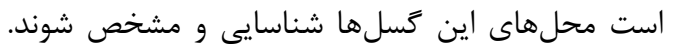

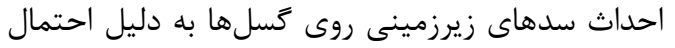

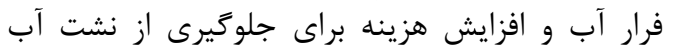

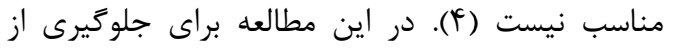

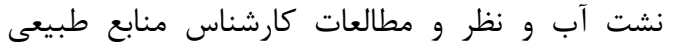

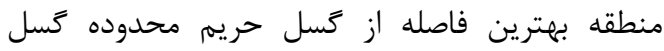

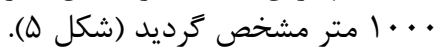

لايه زمينشناسى منطقه مهران: يكى از فاكتورهاى

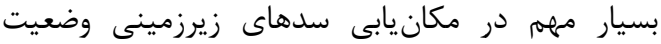

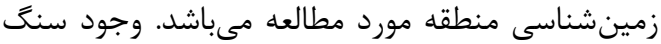

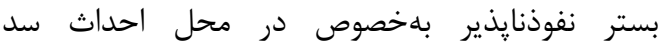

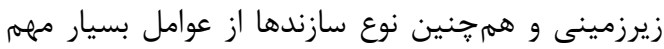

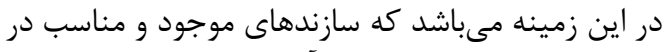

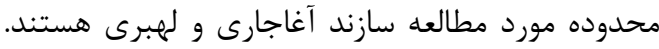

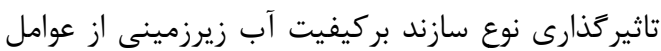

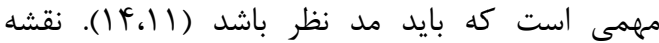
زمينشناسى منطقه مورد مطالعه با استفاده از نقشه ئهاى

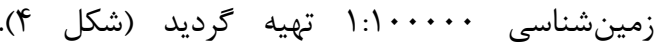
مشخصات سازندهاى زمينشاسناسى منطقه مورد مطالعه در جدول r آورده شده است.

\begin{tabular}{|c|c|c|c|}
\hline \multicolumn{4}{|c|}{ مشخصات سازندهاى زمينشناسى منطقه مورد مطالعه } \\
\hline يتانسيل آبخوان كارستى و سنكى & وسعت (km²) & جنس سازند & 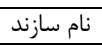 \\
\hline ندارد & If & شيل و آهك شيلى & كرو \\
\hline دارد & $\Delta T \cdot$ & آهك & 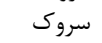 \\
\hline ندارد & 10 . & 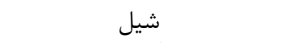 & سور كاه \\
\hline دارد & rt. & آهك & ايلام \\
\hline ندارد & r.. & شيل و آهك مارنى & 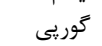 \\
\hline ن ن ارد & rat & آهك مارنى و شيل & يابده \\
\hline 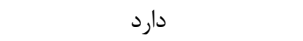 & MET & آهك و انيدريت & 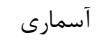 \\
\hline 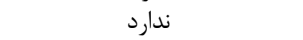 & VVG & انيدريت، كَج و آهك مارنى & كَجساران \\
\hline 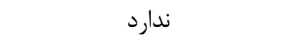 & $\Delta \Lambda$. & ماسهسنَ، سيلتستون و مارن & آغاجارى \\
\hline ندارد & $V \Delta$. & ماسهسنح و سيلتستون & لهبرى ل ل ل \\
\hline دارد & TTS & كنَكلومرا و ماسهسنَ & بختياري \\
\hline
\end{tabular}

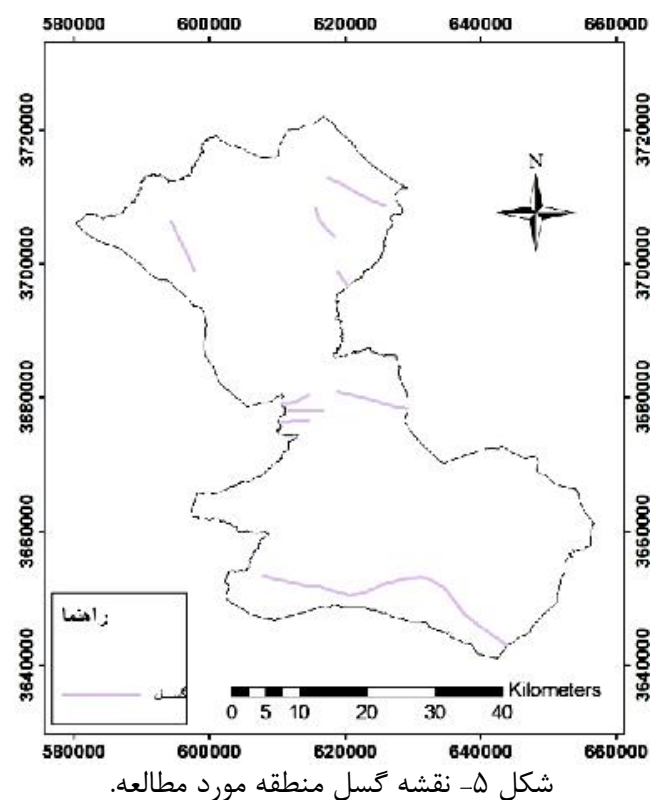

بيشتر باشد آبراهه از رده بالاترى برخوردار بوده و براى

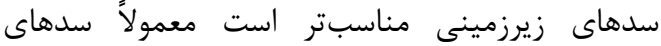

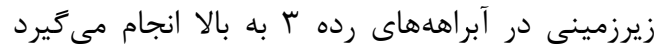

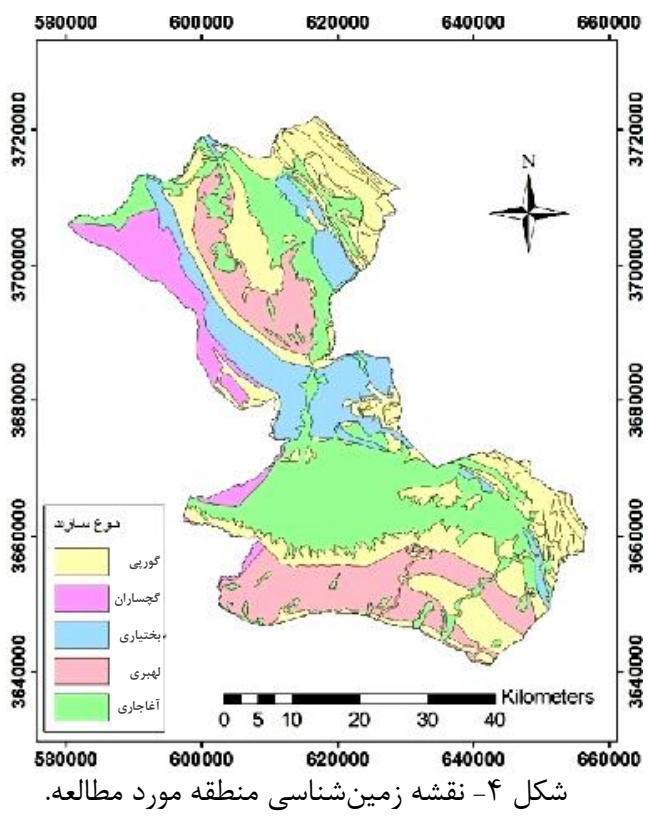

لايه تراكم زهكشى: در مكانيابى سدهاى زيرزمينى

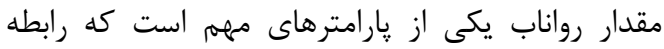

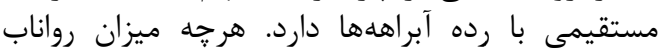




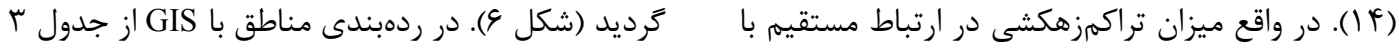

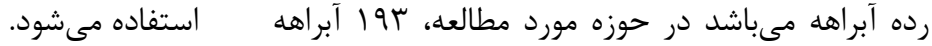

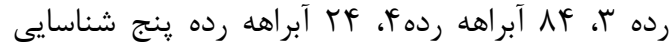

\begin{tabular}{|c|c|}
\hline كلاس تراكم زهكشى & رده آبراهه \\
\hline$<1 / \Delta$ & نامناسب \\
\hline $1 / \Delta-r$ & متوسط \\
\hline$r-r$ & خوب \\
\hline$>r$ & خيلى خوب \\
\hline
\end{tabular}

معرف ارتفاعات در نظر گرفته شده است. از روش معادله

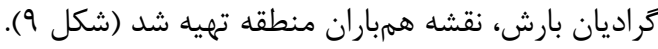

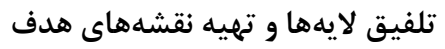

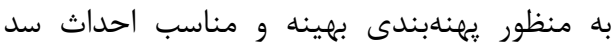
زيرزمينى در منطقه مهران، نقشههاى هر لايه تهيه شده بهد

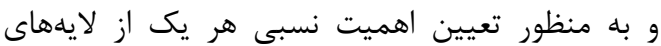

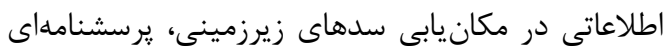

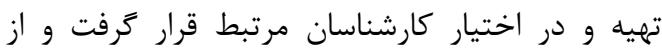

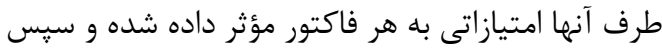

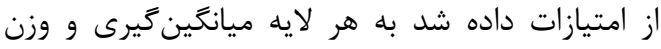

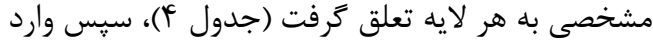

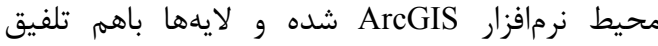

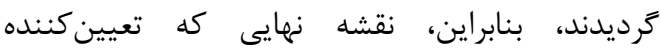

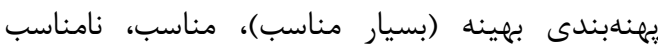

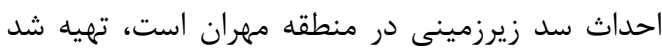

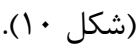

لايه كاربرى اراضى: به منظور تهيه لايه كاربرى اراضى از

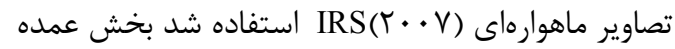

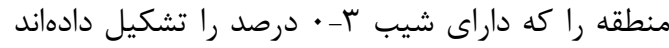

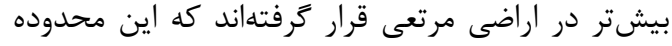

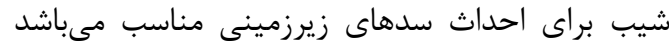

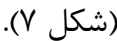

لايههاى دما و بارش: از آنجا كه فاكتور بارش و دما،

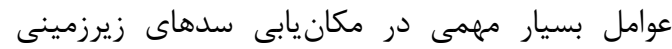

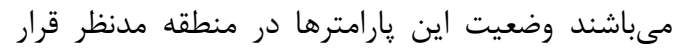

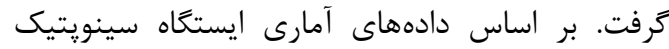

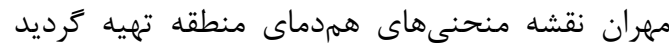

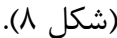

به منظور بررسى تغييرات درازمدت ميران بارش در مر مران

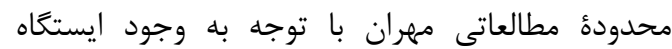

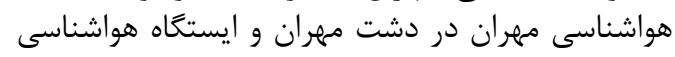

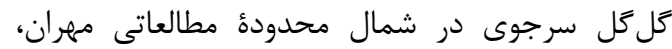

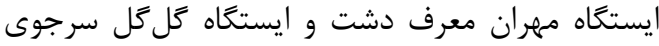

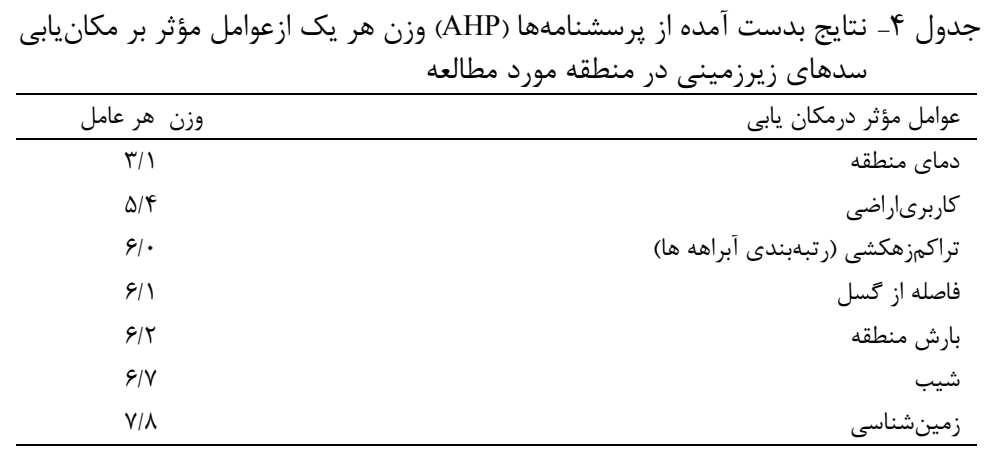



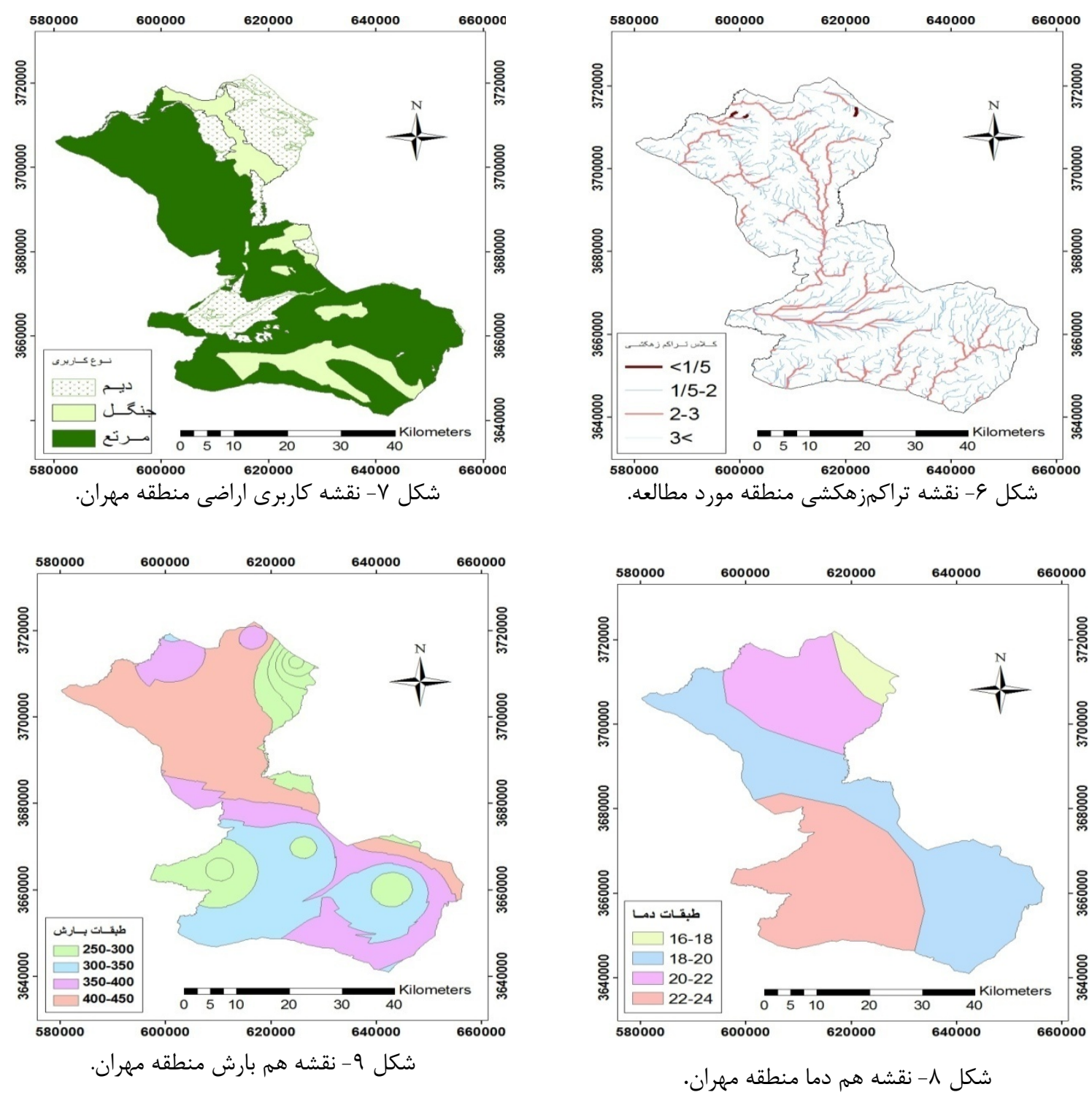

كه از لحاظ فاكتورهاى كفته شده نامناسب بودند، حذف د

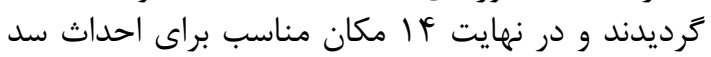

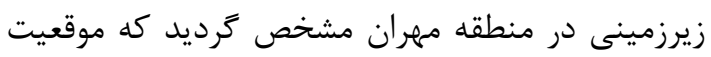

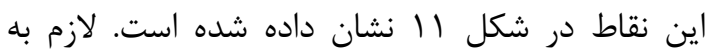

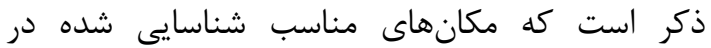

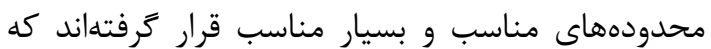

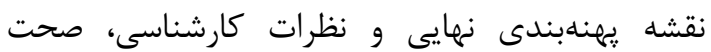

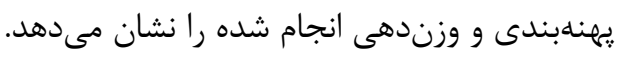

بر اساس مجموعه عوامل مؤثر در مكان يابى سد

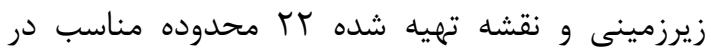

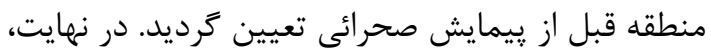

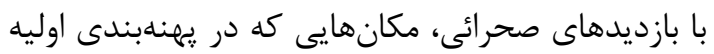

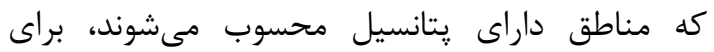

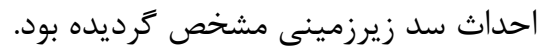

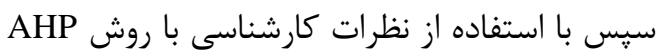

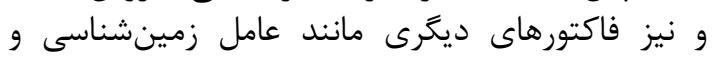

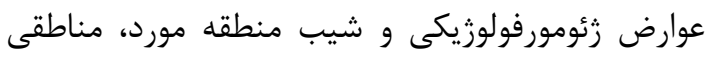




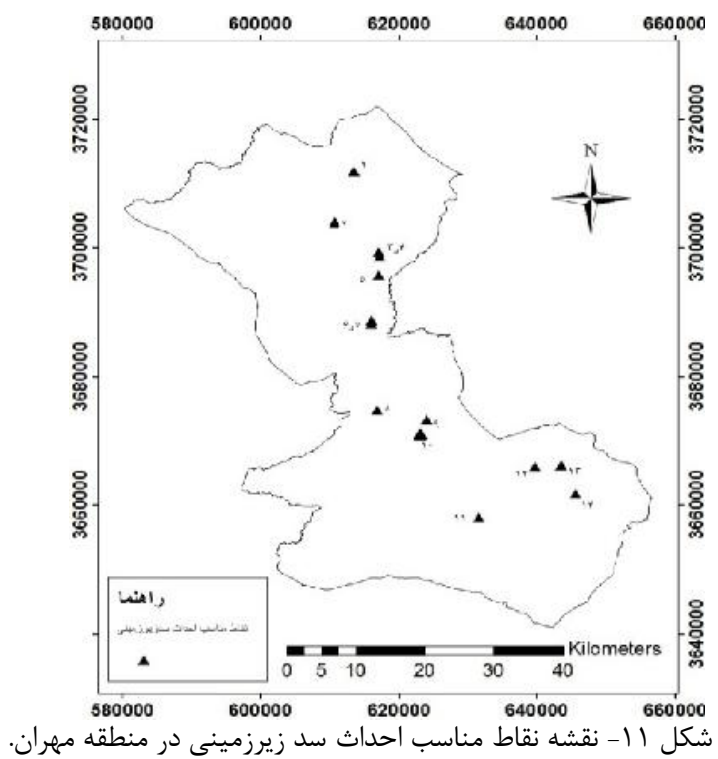

كه نتايج شيب را در بيشترين وسعت كه r ب-1 درصد و

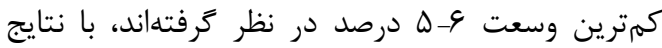

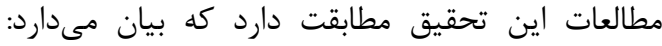

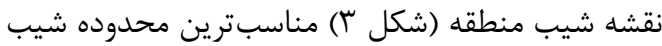

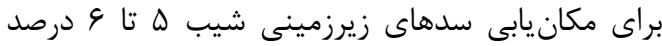

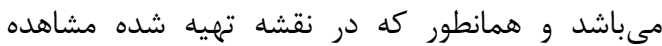

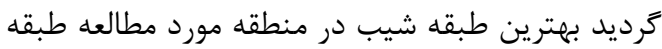

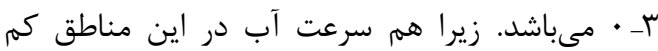

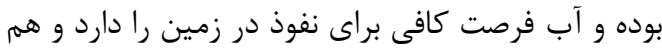

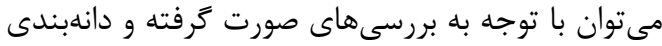
مناسب ذرات موجود در مناطق مستعد انتظار تشكيل مان موريل

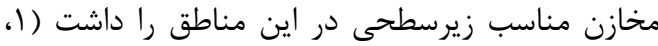

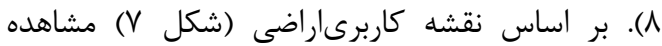
مىشود بخش عمده منطقه را اراضى ارئ مرتعى تشكيل

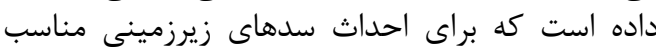

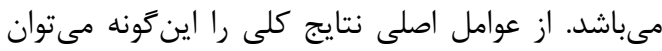

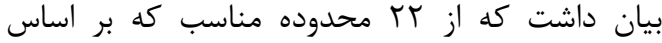

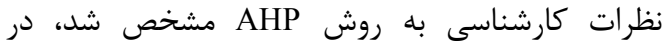

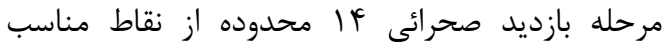

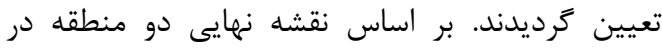

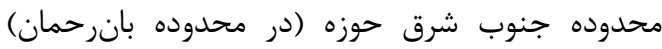

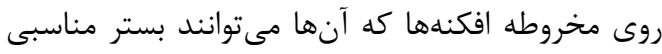

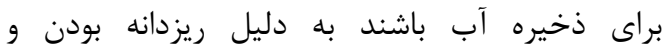

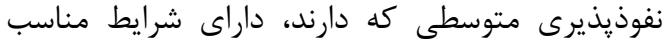

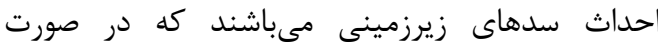

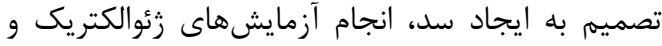

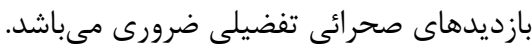

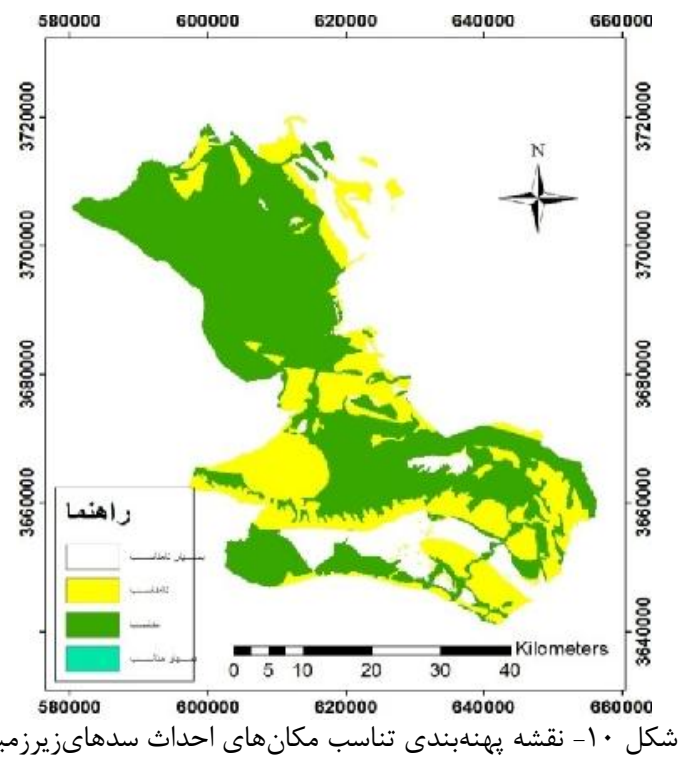

نتايج و بحث

بررسى نتايج حاصل از اين تحقيق با تحقيق

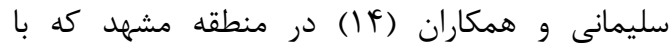

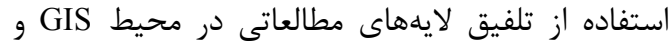

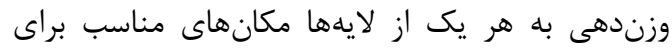

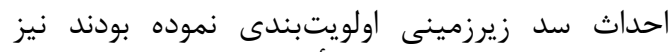

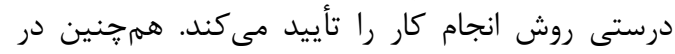

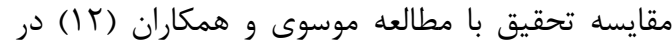

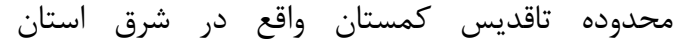

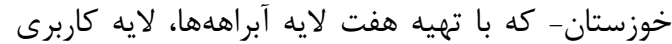

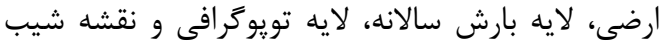

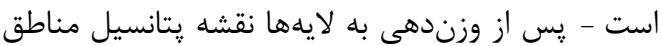

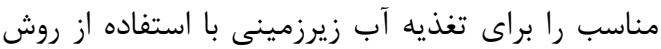

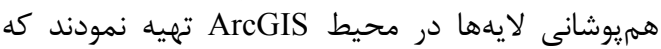

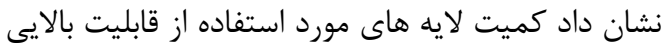

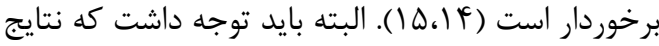

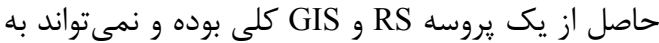

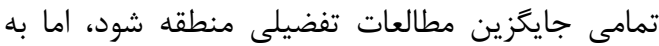

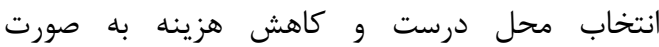

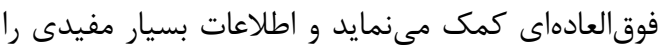

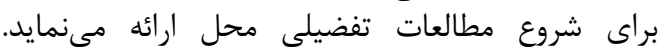
همجنين مطالعات دماوندى و همكاران (r) كه بـ براى

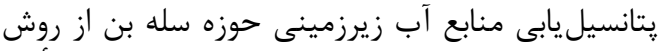

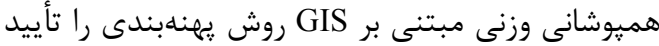

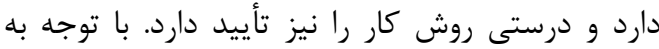

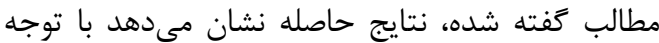

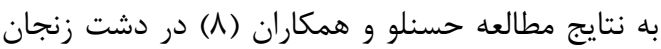


1. Amini Bezenjani, M., G. LashKaripoor and M. Ghafouri. 2011. Monitoring Methodology of Underground Dam (Case study: Ravor Underground dam). Journal of Irrigation and Water Engineering, 1: 43-57 (In Persian).

2. Burger, S.W. and R.D. Beaumont. 1970. Sand Storage Dams for Water Conservation. Conurntion: Water for the Future. Water Year 1970. Republic of South Africa, 9 pp.

3. Damavandi, A.A., F. Rezaei and M. Panahi. 2011. Locating Groundwater Resources by Using Remote Sensing and GIS (Case Study: Salebon Catchment). Second National Geosciences Conference. Zanjan Azad University, 1: 321-330 (In Persian).

4. Danaie, R., M. Hasanzadeh Nafoti, S. Mohtashamnia and M.R. Danaeian. 2011. Locating of Underground Dams with Using RS/GIS (Case Study: Manshad of Yazd province). The First National Conference on Economic Resolutions in the Field of Agriculture, 1: 146-151 (In Persian).

5. Foster, S., G. Azevedo and A. Baltar. 2002. Subsurface Dams to Augment Round Water Storage in Basement Terrain for Human Subsistence: Brazilian Experience. Universidad Federal, 82: 49-56.

6. Forzieri, G., M. Gardenti, F. Caparrini and F. Castelli. 2008. A Methodology for the Pre-Selection of Suitable Sites for Surface and Underground Small Dams in Arid Areas: A Case Study in the Region of Kidal, Mali. Physics and Chemistry of the Earth, Parts A/B/C, 33: 74-85.

7. Hanson, G. and A. Nilsson. 1986. Ground-Water Dams for Rural-Water Supplies in Developing Countries. Ground Water, 24: 497-506.

8. Hasanloo, M.R., J. Khalafi and M. Hashemi. 2009. Locating Appropriate Areas for Groundwater Dams by Using Satellite Imagery in Zanjan Plain. Second National Dam Engineering Conference. Zanjan Azad University, 1: 204-213 (In Persian).

9. Ishida, S., M. Kotoku, E. Abe, M.A. Fazal, T. Tsuchihara and M. Imaizumi. 2003. Construction of Subsurface Dams and Their Impact on the Environment. Materials and Geoenvironment, 50: 149-152.

10. Jacks, G., V.P. Sharma and G.K. Sharma. 1980. Hydrochemical Studies, Sida-Assisted Groundwater Project in Kerala, a Report, 1: 1-5.

11. Laa, A., M. Kampanart and S. Kriengsak. 2005. Approachability of Subsurface Dams in the Northeast Thailand. International Conference on Geology, Geotechnology and Mineral Resources of Indochina (GEOINDO 2005), 28-30 November 2005, Khon Kaen, Thailand. 1: 149-155.

12. Mosavi, S.F., M. Chitsazan and Y. Mirzaei. 2009. Integration of Remote Sensing and GIS for Mapping Appropriate Areas to Groundwater Recharge (Case Study, Komestan Area), Geomatics conference, Tehran, 1: 183-192 (In Persian).

13. Nilsson, A. 1988. Groundwater Dams for Small-Scale Water Supply. Intermediate Technology Publications, $76 \mathrm{pp}$.

14. Solimani, S., M.R. Nikdel, A. Oromiehei and A. Bahrami. 2008. Locating the Appropriate Factors for Underground Dams Using GIS and RS, $3^{\text {th }}$ Iran Water Resources Management Conference, 1: 234239 (In Persian).

15. Tabatabeiyazdi, J. and S. Nabipaylashkaryian. 2004. Dams of Groundwater in the Small Scale. Research Center of Conservation of Watershed Management and Soil, $63 \mathrm{pp}$ (In Persian).

16. Telmer, K. and M. Best. 2004. Underground Dams: a Practical Solution for the Water Needs of Small Communities in Semiarid Regions. TERRA, 1: 63-65.

17. Vanrompay, L. 2003. Report on the Technical Evaluation and Impact Assessment of Subsurface Dams (SSDs). TLDP Technical Report, 14 pp. 


\title{
Mapping underground Dam in Arid and Semi-Arid Area in Western Iran (Case Study: Mehran, Ilam Province)
}

\author{
1 and 3- Graduated M.Sc. and Associate Professor, Ilam University \\ 2- Assistant Professor, Ilam University (Corresponding author: faramarzi.marzban@gmail.com) \\ 4- M.Sc., Natural Resources and Watershed Management Organization, Ilam Province \\ 5- M.Sc., Ilam Regional Water Company \\ Received: July 26, $2014 \quad$ Accepted: June 13, 2015
}

\begin{abstract}
Management of underground resources has a special priority in arid and semi-arid in Iran. Increasing underground resources is one of the useful ways for providing water requirements during the drought years. The main objective of this study was for mapping underground dam in the arid and semi-arid area in western Iran. The first and important stage of underground dam construction is recognizing an appropriate location of dam. In this research, after investigating the previous study and improving some basic information, different layers were integrated using GIS technology to determine the location which has a potential for these structures in the study area. These layers were including fault, slope, geology, geomorphology, rainfall, temperature and land use. The IRS satellite imagery in 2007 was used for providing the geomorphology map and land use map as well as well to determine the correct location of dams. Then, a number of 14 appropriate locations were selected using field data collection and the AHP method for constructing the underground dams in the study area.
\end{abstract}

Keywords: GIS, Ilam Province, Mehran Plain, Underground Dams 